\title{
IDENTIFICAÇÃO E AVALIAÇÃO dAS AÇÕES INSTITUCIONAIS E POLÍTICAS PÚBLICAS COM FOCO NAS DEMANDAS DO ARRANJO PRODUTIVO LOCAL (APL) DE BONÉS DE APUCARANA NO ESTADO DO PARANÁ
}

\author{
Antonio Carlos de Campos' \\ Rafaella Stradiotto Vignandi²
}

\begin{abstract}
Resumo
O objetivo do estudo é evidenciar as demandas apresentadas pelos empresários do setor de bonés de Apucarana, bem como identificar e avaliar as ações institucionais e políticas públicas, visando às necessidades apontadas no relatório do IPARDES em 2006. Os dados utilizados são da RAIS/MTE e da Secretaria Estadual da Fazenda. Uma metodologia aplicada foi o cálculo do QL. Os resultados evidenciaram uma evolução satisfatória das demandas identificadas, com alto grau de interação entre os Governos, as instituições e o empresariado local, permitindo que as demandas fossem parcialmente supridas. Os números de estabelecimentos e empregos formais aumentaram nos primeiros anos analisados, mas posteriormente o APL sentiu os efeitos da crise financeira internacional. Por meio do QL revelou-se que o arranjo mantém-se especializado, evidenciando os efeitos positivos ao desenvolvimento setorial-regional.
\end{abstract}

Palavras-chave: Arranjos Produtivos Locais, confecção de Bonés, Apucarana.

Classificação JEL: R11, L67

Doutor em Desenvolvimento Econômico pela Universidade Federal do Paraná (UFPR) e Professor do Departamento de Economia da Universidade Estadual de Maringá (UEM). E-mail: accampos@uem.br

2 Graduanda em Ciências Econômicas pela Universidade Estadual de Maringá (UEM) e Bolsista do programa PIBIC/ CNPq-FA-UEM. E-mail: rafaellasv@gmail.com 
Identificação e avaliação das ações institucionais e políticas públicas com foco nas demandas do Arranjo Produtivo Local (APL) de bonés de Apucarana no Estado do Paraná

\section{INTRODUÇÃO}

As instituições públicas brasileiras, especialmente as universidades, têm realizado estudos com vistas à identificação e caracterização de Arranjos Produtivos Locais (APLs) em todo o país. Tais estudos têm possibilitado a abertura de discussões relativas a políticas de apoio, públicas ou privadas, que venham a favorecer as várias atividades industriais que apresentam características de aglomeração.

O objeto de análise tem sido as aglomerações, nas quais pode se verificar especialização setorial e uma trajetória histórica de construção de identidade local em torno de uma atividade. A partir desse ambiente local, passam a existir maior integração, cooperação e, principalmente, confiança entre os agentes os quais, portanto, tornam-se mais propícios à construção de formatos organizacionais com características de um arranjo produtivo local.

As características dos APLs fundamentam-se em elementos como a proximidade geográfica entre as firmas, os quais estimulam um processo de interação local e vêm a viabilizar uma ampliação da eficiência produtiva e proporcionar um ambiente favorável à elevação da competitividade das empresas.

Sob esta perspectiva teórica, inúmeros arranjos produtivos têm sido identificados e caracterizados em várias regiões do mundo, e também no Brasil. Nesse último caso esse processo tem se intensificado, notadamente, desde a década de 1990.

Os estudos pioneiros de arranjos produtivos no Brasil compreenderam vários setores da indústria de transformação, tradicionais na sua maior parte, estando entre eles o de produção de artigos de confecção. Alguns aglomerados dessa atividade são os principais entre aqueles que têm sido pesquisados e passaram a ser considerados casos exemplares de APLs no país.

Alguns dos principais arranjos do setor de confecções estão localizados no estado do Paraná, o qual tem desenvolvido, principalmente por meio de suas instituições públicas, diversos estudos de identificação dos mesmos. Nesse sentido, pode-se citar o papel desempenhado pela Rede APL Paraná, organizada pela Secretaria de Estado e Planejamento (SEPL) do Estado do Paraná. Esse grupo composto por representantes do governo estadual, universidades, bancos e empresários, tem apresentado os resultados dos estudos 
de caso por meio do Instituto Paranaense de Desenvolvimento Econômico e Social (IPARDES), órgão vinculado à SEPL. Entre os 22 casos analisados e considerados APLs, encontra-se o localizado no município de Apucarana, especificamente na atividade de confecção de bonés.

Em um trabalho realizado pelo IPARDES, divulgado em 2006, várias demandas foram levantadas pelos empresários. Na tentativa de compreender esta realidade, algumas questões são levantadas: Em que medida as demandas apontadas pelos empresários da atividade de confecção de bonés de Apucarana foram atendidas? Quais foram às ações desenvolvidas pelas instituições de apoio locais em atendimento as demandas apresentadas no trabalho realizado pelo IPARDES? Houve políticas de apoio por parte do governo do estado do Paraná? Em caso afirmativo, quais foram essas políticas? São algumas questões que precisam ser respondidas com o propósito de se averiguar e medir o alcance das proposições do projeto pensado e elaborado pela SEPL e IPARDES, em conjunto com as instituições de Ensino Superior do Estado do Paraná (IEES) ${ }^{3}$.

No caso específico do setor de bonés de Apucarana, há uma sistematização de demandas, desde aquelas que dependem das instituições de apoio localizadas no município até mesmo aquelas que dependem de políticas públicas em níveis Federal, Estadual e Municipal. É neste sentido que torna-se importante investigar o que de fato foi realizado pelas instituições de apoio e pelos governos enquanto políticas públicas, com foco específico ao atendimento das demandas reveladas pelos empresários.

O objetivo central do presente estudo consiste em evidenciar as demandas apresentadas pelos empresários do setor de confecção de bonés de Apucarana, identificar e avaliar as ações institucionais e as políticas públicas que foram desenvolvidas, com foco nessas necessidades.

$\mathrm{O}$ artigo encontra-se estruturado em mais quatro seções, além desta introdução. A segunda seção apresentará a fundamentação teórica, baseada na abordagem dos Arranjos Produtivos Locais. Na seção seguinte, expõe-se a metodologia utilizada no estudo. A quarta seção, consistirá na apresentação dos resultados, onde será examinado em contexto nacional e estadual recente o setor de confecção e especificamente o APL de bonés de

Fazem parte deste Projeto a Universidade Estadual de Londrina (UEL), Universidade Estadual de Maringá (UEM), Universidade Estadual de Ponta Grossa (UEPG), Universidade Estadual do Oeste Paranaense (Unioeste Francisco Beltrão) e a Universidade Estadual do Oeste Paranaense (Unioeste de Toledo). 
Identificação e avaliação das ações institucionais e políticas públicas com foco nas demandas do Arranjo Produtivo Local (APL) de bonés de Apucarana no Estado do Paraná

Apucarana. Esta seção, ainda, evidenciará as principais demandas apresentadas pelos empresários locais, bem como as ações institucionais e políticas públicas desenvolvidas em prol do arranjo ao longo do período estudado. Finalmente, na quinta e última seção, serão tecidas algumas considerações finais que incluirão as principais conclusões a respeito do desenvolvimento das necessidades do APL em questão.

\section{FUNDAMENTAÇÃO TEÓRICA}

Com base nos estudos realizados por Alfred Marshall no fim do século XIX sobre Distritos Industriais, derivados de um padrão organizacional comum a Inglaterra, pode-se observar a existência de uma relação benéfica entre a sociedade local e as instituições privadas localizadas em um espaço geográfico e histórico.

A concentração, a proximidade, a especialização, a integração e a divisão do trabalho proporcionam vantagens de economias de escala, possibilitando o surgimento das economias externas em locais que articulam atividades similares. “(...) passamos, agora, a examinar aquelas importantes economias externas que frequentemente podem ser adquiridas pela concentração de muitos pequenos negócios de caráter similar em localidades particulares" (MARSHALL, 1982, p.221).

O autor supracitado ainda afirma que a especialização da mão-de-obra e a concentração de aglomerações produtivas locais que desenvolvem atividades equivalentes atuam no fornecimento direto de matérias-primas e insumos servindo de suporte para as indústrias principais favorecendo e consolidando a estrutura do distrito industrial. Observam-se, neste sentido, benefícios e eficiência coletiva oriundos de uma concentração industrial.

A idéia de economias externas introduzidas por Alfred Marshall, no final do século XVIII, contribuiu significativamente para o desenvolvimento da chamada eficiência coletiva. Para Schmitz (1997, p.165), a eficiência coletiva define-se "como a vantagem competitiva derivada de economias externas locais e ação conjunta (joint action)".

Por identificar a necessidade de um conceito integrador, que capte a essência de que a viabilidade econômica não pode ser compreendida e nem aprimorada, focalizando as firmas individuais que Schmitz (1997, p.173) propôs o conceito de eficiência coletiva. Ou em outras palavras, há a eficiência co- 
letiva não planejada (incidental) e a planejada (conscientemente perseguida) ${ }^{4}$, conhecidas também como passiva e ativa (NADVI; SCHMITZ, 1999).

O ambiente competitivo e conflitante existente entre as firmas não é excluído pela noção de eficiência coletiva; pelo contrário, as formações desses arranjos produtivos locais tornam o mercado mais transparente e estimula a rivalidade entre eles. A caracterização dessa competição agregadora depende do comprometimento, participação e interação dos agentes envolvidos, via empresas, produtoras de bens e serviços finais, fornecedoras de insumos e equipamentos, clientes; da cooperação e ações conjuntas; da geração e compartilhamento do conhecimento, da capacitação produtiva e inovativa das organizações, por meio das instituições de apoio que incluem universidades, organizações de pesquisa, empresas de consultoria e de assistência técnica, órgãos públicos, organizações não governamentais, entre outros; e da estrutura de governança que refere-se aos diversos modos de coordenação entre os agentes e atividades (LASTRES; CASSIOLATO, 2003).

A teoria dos pólos de desenvolvimento, introduzida por François Perroux (1975) tem a seguinte premissa fundamental: o desenvolvimento econômico no modelo capitalista acontece de maneira polarizada, há regiões que se transformam em pólos de desenvolvimento atraindo capital, investimentos e mão-de-obra, e outras que se voltam para pólos de repulsão. “(...) o crescimento não surge em toda parte ao mesmo tempo; manifesta-se com intensidades variáveis, em pontos ou pólos de crescimento; propagase, segundo vias diferentes e com efeitos finais variáveis, no conjunto da economia" (PERROUX, 1975, p. 100).

Perante a essa idéia, se constituem na economia dos pólos de desenvolvimento com as indústrias motrizes (chaves) e as indústrias movidas. As indústrias motrizes podem aumentar o volume de produção para utilizar sua capacidade plenamente e de forma a maximizar os capitais fixos, a fim de diminuir gradativamente os custos de produção. Ao atingir o ótimo da produção, a menos que se trate de um monopólio, poderá reduzir o preço, o que induzirá a novos incrementos do volume de produtos das indústrias

\footnotetext{
4 Na eficiência coletiva não planejada os ganhos são não intencionais, ou seja, da própria existência da aglomeração industrial, a qual fornece custos reduzidos (economias externas marshallianas). A eficiência coletiva planejada é resultante de ações conjuntas deliberadas de empresas e de instituições locais. As ações conjuntas podem, ainda, ser divididas em dois grupos. As primeiras ocorrem através de firmas individuais cooperando entre si, ao passo que as do segundo grupo ocorrem através de grupos de firmas reunindo forças em associações empresariais, consórcios de produtores, sindicatos e outros (CAMPOS; PAULA, 2006, p.35-36).
} 
Identificação e avaliação das ações institucionais e políticas públicas com foco nas demandas do Arranjo Produtivo Local (APL) de bonés de Apucarana no Estado do Paraná

movidas. Com isso, atraem-se novos empregos e intensifica-se o encadeamento da entrada de novas empresas (PERROUX, 1975, p.106).

Uma região dinâmica pode acarretar no aparecimento de "zonas de desenvolvimento", que reúnem as economias conglomeradas enquanto o vínculo entre os pólos dinâmicos da economia originam os "eixos de desenvolvimento" na região, o que é concretizado pela instalação de uma infra-estrutura integrada economicamente na região no quesito dinamização do processo produtivo. No capitalismo, o desenvolvimento é polarizado porque as atividades econômicas buscam lugares que proporcionem a eles vantagens locacionais.

De acordo com a economista americana Ann Markusen ${ }^{5}$ (1995, p.14), pode-se definir pólo ou distrito industrial (sticky place) de acordo com as seguintes condições: i) obtenção na região de taxas de crescimento na média ou acima da média em relação a outras localidades; ii) capacidade local de se evitar falências e/ou perdas de postos de trabalho decorrentes dos efeitos das oscilações de curto e médio prazo, tanto referentes aos ciclos dos negócios e/ou em relação aos gastos públicos; iii) oferta de bons empregos, a contenção das tendências de segmentação salarial e a prevenção de excessiva concentração da renda e da propriedade; iv) livre organização dos trabalhadores e sua participação nos processos decisórios das firmas e; v) o incentivo à participação e a contestação política em âmbito regional.

Para esta autora, os distritos industriais tradicionais referem-se à existência de cooperação entre todas as firmas e agentes externo. Nos distritos centro-radiais ( $h u b$ and spoke) os agentes organizam-se em torno de uma firma chave, formando assim eixos de economia regional, ou seja, congregando em torno de si fornecedores e outras atividades correlatas. As plataformas satélites são organizadas fora dos centros urbanos, cujo sistema é estimulado por governos nacionais e/ou estaduais como forma de desenvolvimento regional, onde as atividades desenvolvidas podem variar desde simples rotinas de montagem (low-end-cases) até pesquisas sofisticadas (high-end-cases). Por fim os distritos sustentados pelo governo, nos quais os agentes encontram-se organizados em torno de uma entidade não lucrativa ou pública, seja de base militar, universitária, um centro de

MARKUSEN, Ann é doutora pela Michigan State University (MSU), atualmente é diretora do Instituto de Economia Regional e Industrial (Humphrey Institute Public Affairs) e professora da University of Minessota. Pesquisadora na área de economia e desenvolvimento regional. 
pesquisa ou laboratório ligado ao setor bélico, um complexo prisional ou uma grande concentração de órgãos públicos, diferencia-se pelo fato da estrutura de negócios locais não ser caracterizada pela presença de instituições privadas (MARKUSEN, 1995, p. 15).

Um dos fundamentos do Arranjo Produtivo Local (APL) está no conceito de Aprendizado. Para a Ciência Econômica esse conceito pode estar relacionado a um processo cumulativo em que por meio de recursos humanos esse conhecimento é adquirido e ampliado, lapidando as habilidades com o objetivo de desenvolver, produzir e comercializar bens e serviços. Pela ótica empresarial (schumpeteriana), um impacto positivo advindo das divergentes etapas do aprendizado é o incremento da eficiência produtiva e administrativa, proporcionado por um processo de inovação mais dinâmico.

Existem algumas formas de aprendizado que são de extrema importância ao processo de inovação e ao desenvolvimento de capacitações produtivas, tecnológicas e organizacionais, tais como: aprendizagem a partir de fontes internas à firma, que incluem o aprendizado por experiência/ vivência própria, no processo produtivo (learning by doing), no comércio e uso (learning by using), e na procura por soluções inéditas em estudos/casos de pesquisa e desenvolvimento (learning by searching); e aprendizagem a partir de fontes externas, o que engloba processo de compra, cooperação e interação entre fornecedores (matérias-primas, insumos, máquinas e equipamentos), concorrentes, clientes, usuários, sócios, consultores, instituições de apoio (learning by interacting and cooperating) e aprendizagem por imitação (learning by imitating) (JOHNSON e LUNDVALL, 2003 apud LASTRES e CASSIOLATO, 2003).

O conhecimento também é uma forma de aprendizado, segundo Michael Polanyi (1958) e Joseph Schumpeter (1988) e pode ser classificado como: codificado, que incorpora o conhecimento de maneira formalizada e estruturada, podendo ser manipulado como informação, através da comunicação formal entre os agentes; e tácito, que incorpora o conhecimento em crenças, valores, saberes e habilidades individuais ou da instituição. O conhecimento tácito pode estar relacionado a contextos organizacionais ou geográficos específicos, como é o caso de arranjos produtivos locais.

De acordo com Johnson e Lundvall pode-se classificar o conhecimento codificado e tácito em quatro diferentes categorias: "conhecer o quê" (know- 
Identificação e avaliação das ações institucionais e políticas públicas com foco nas demandas do Arranjo Produtivo Local (APL) de bonés de Apucarana no Estado do Paraná

what), referente aos fatos, informações; "conhecer por que" (know-why), referente à princípios, leis naturais e sociais, conhecimento científico; "conhecer como" (know-how), referente às capacitações que permitem fazer algo - conhecimento tácito; "conhecer quem" (know-who), referente ao 'quem sabe o que' e 'quem sabe como fazer o que' (JOHNSON e LUNDVALL, 2003 apud LASTRES e CASSIOLATO, 2003; LUNDVALL, 1996).

A natureza e a intensidade das interações entre os membros do arranjo repercutem nas condições do ambiente econômico, social, cultural e institucional ao qual estão inseridos. Uma análise da especificidade e do dinamismo institucional de APLs é essencial para o entendimento do processo de capacitação produtiva e inovativa.

Joseph Schumpeter (1988), em seu livro Teoria do Desenvolvimento Econômico, propõe que a inovação cria uma interrupção na continuidade do sistema econômico, no interior das indústrias, transformando as estruturas produtivas e criando fontes de diferenciação para as empresas. Foi a partir de um processo contínuo de destruição criativa, criando novas formas de organização, novos produtos e novos materiais que Schumpeter mostrou como ocorria a dinâmica da economia capitalista, isto é, o "novo" destruindo o "velho" (NAPOLEONI, 1990, p.51).

Outro fundamento presente nos Arranjos Produtivos Locais é a Cooperação, trabalho coletivo que envolve relações de confiança mútua e coordenação entre os integrantes. Nos arranjos podem-se identificar diferentes formas de ações conjuntas que visam à cooperação produtiva com o intuito de ganhos de economia de escala e escopo, assim como melhores índices de qualidade e produtividade e a cooperação inovativa, que consiste em redução de custos, riscos, tempo e a dinamização da inovação do APL.

A cooperação pode acontecer por meio de intercâmbio de informações produtivas, tecnológicas e mercadológicas; integração envolvendo empresas e outras instituições, como cursos, seminários e feiras que agem como catalisadores para novas idéias e inovações adicionais tanto para os produtores como para os compradores (NADVI; SCHMITZ, 1999); integração de competência, realizando projetos conjuntos entre empresas e organizações (LEMOS, 2002).

A caracterização de Arranjos Produtivos Locais (APL), de acordo com Lastres e Cassiolato (2003) pode ser apresentada por: i) dimensão 
territorial, que é quando os processos produtivos, inovativos e cooperativos assumem um espaço; ii) a proximidade e concentração geográfica, que agrega e compartilha valores sociais, econômicos e culturais, bem como as vantagens comparativas em relação a outras áreas; iii) a diversidade de atividades e atores econômicos, políticos e sociais, envolvendo empresas, universidades, organizações públicas e privadas, consultorias, entre outras instituições; iv) o conhecimento tácito, que é implícito e incorporado aos indivíduos, organizações e regiões; v) a inovação e o aprendizado interativo, transmitindo conhecimentos e ampliando a capacitação produtiva das empresas, para garantir a competitividade individual e do coletivo; e, vi) a governança, com diferentes modos de coordenação entre os agentes, atividades e grau de enraizamento, mensurando as articulações e o envolvimento dos diferentes agentes dos APLs com capacitação e recursos humanos, naturais, técnico-cientificos, financeiros, assim como as demais organizações e o mercado consumidor locais.

Com base nos elementos expostos e em uma definição adotada pela Rede de Pesquisa em Sistemas Produtivos e Inovativos Locais (REDESIST) $)^{6}$, Arranjos Produtivos Locais são "aglomerações territoriais de agentes econômicos, políticos e sociais - com foco em um conjunto específico de atividades econômicas - que apresentam vínculos mesmo que incipientes. Geralmente envolvem a participação e a interação de empresas - que podem ser desde produtoras de bens e serviços finais até fornecedoras de insumos e equipamentos, prestadoras de consultoria e serviços, comercializadoras, clientes, entre outros - e suas variadas formas de representação e associação. Incluem também diversas outras organizações públicas e privadas voltadas para: formação e capacitação de recursos humanos, como escolas técnicas e universidades; pesquisa, desenvolvimento e engenharia; política, promoção e financiamento".

Uma tipologia desenvolvida por Suzigan et al. (2003), possibilitou o tratamento dos diferentes níveis de consolidação dos Arranjos Produtivos Locais. Os arranjos que se destacam pela elevada importância local e setorial denominam-se núcleos de desenvolvimento setorial-regional. Os

\footnotetext{
6 A Rede de Pesquisa em Sistemas Produtivos e Inovativos Locais - REDESIST é uma rede de pesquisa interdisciplinar, formalizada desde 1997, sediada no Instituto de Economia da Universidade Federal do Rio de Janeiro. Conta com a participação de várias universidades e institutos de pesquisa no Brasil, além de manter parcerias com outras organizações internacionais. Disponível em: http://www.redesist.ie.ufrj.br.
} 
Identificação e avaliação das ações institucionais e políticas públicas com foco nas demandas do Arranjo Produtivo Local (APL) de bonés de Apucarana no Estado do Paraná

arranjos que tem uma elevada importância para o setor, como a participação na produção ou emprego e apresentam pouca importância para o local são chamados de vetores avançados. Os arranjos que são importantes para a região (local), mas não contribuem para o setor são denominados vetores de desenvolvimento local. E os arranjos que possuem pouca importância para o setor e convivem ao mesmo tempo com outras atividades econômicas em uma região, apresentando-se com baixa importância local são considerados embriões de arranjos produtivos.

\section{METODOLOGIA}

O estudo sobre o Arranjo Produtivo Local de Apucarana aborda a Confecção de Artigos do Vestuário e Acessório (Divisão 14), de forma mais específica, a Fabricação de acessórios do vestuário, exceto para segurança e proteção, composta pela fabricação de gravatas, lenços, cintos, suspensórios, luvas (inclusive de couro), leques, xales, echarpes, chapéus, boinas, bonés, gorros e outros (Classe 1.414-2).

O material publicado em 2006, sobre o tema de Identificação, Caracterização, Construção de Tipologia e Apoio na Formulação de Políticas para Arranjos Produtivos Locais (APLs) pelo Instituto Paranaense de Desenvolvimento Econômico e Social (IPARDES) ${ }^{7}$ e pelas Instituições Estaduais de Ensino Superior (IEES), com apoio da Secretaria de Estado do Planejamento e Coordenação Geral (SEPL) servirá de base para este estudo.

As ações desenvolvidas pelas instituições de apoio locais serão identificadas a partir de consultas diretas a estes órgãos. Além da utilização de dados secundários da Relação Anual de Informações Sociais do Ministério do Trabalho e Emprego (RAIS/MTE) e informações presentes nos sítios eletrônicos do governo Federal e também por consultas na Secretaria Estadual da Fazenda (SEFA) do governo estadual do Paraná.

Para analisar a participação relativa do emprego do APL em relação ao emprego estadual será utilizado o Quociente Locacional (QL), o qual tem sua origem, como indicador de localização ou especialização, no trabalho de Isard (1960) e vem sendo amplamente utilizado nos estudos de econo-

Disponíveis em http://www.ipardes.gov.br 
mia regional. Trata-se de um indicador utilizado para determinar o grau de especialização de uma região ou município em uma atividade específica. O QL foi definido por Haddad (1989) e pode ser apresentado como:

$$
Q L_{i, j}=\frac{\frac{E_{j}^{i}}{E_{j}}}{\frac{E_{j j}^{i}}{E_{j j}^{i i}}}
$$

Onde: $E_{j}^{i}=$ Emprego da atividade industrial $i$ na região $j ; E_{j}=$ Emprego industrial total na região $j ; E_{j j}^{i}=$ Emprego da atividade industrial $i$ em todas as regiões; $E_{j j}^{i i}=$ Emprego industrial total em todas as regiões.

\section{RESULTADOS E DISCUSSÕES}

\subsection{O setor têxtil-confeccionista no Brasil e no Paraná}

A indústria de confecção brasileira é o subgrupo mais significativo da cadeia têxtil-confecção no que tange a empregabilidade e a geração de renda, e atualmente corresponde a um dos mais importantes complexo-industriais do Brasil. A geração potencial de empregos é um fator de extrema relevância que situa o setor entre os mais importantes da indústria tradicional.

Segundo os dados disponibilizados pela Associação Brasileira da Indústria Têxtil e de Confecção (ABIT) ${ }^{8}$, RAIS/MTE e IBGE a atividade empregava formalmente 1,65 milhões de trabalhadores no ano de 2008 em todo o Brasil, sendo a segunda atividade do ramo que mais emprega e a segunda maior geradora do primeiro emprego. A estatística não leva em consideração os vínculos informais, pois são de difícil mensuração, todavia muito significativos neste setor.

Em termos de faturamento no ano de 2008, a receita bruta da confecção nacional atingiu o nível de US\$47 bilhões, representando 17,5\% do PIB da indústria de transformação. Ao se comparar essa receita com o PIB total do país, a participação da atividade é de 3,5\% (ABIT, 2008).

Disponível na página eletrônica da Associação Brasileira da Indústria Têxtil e de Confecção na subseção dos Relatórios Anuais em: http://www.abit.org.br. 
Identificação e avaliação das ações institucionais e políticas públicas com foco nas demandas do Arranjo Produtivo Local (APL) de bonés de Apucarana no Estado do Paraná

O setor têxtil-confeccionista do Paraná destaca-se, tanto na geração de emprego e renda, como em razão da crescente representatividade na especialização produtiva, com ênfase nas aglomerações empresariais paranaenses especializadas na confecção de jeans (Maringá, Londrina e Cianorte) ${ }^{9}$ (OLIVEIRA, CÂMARA e BAPTISTA, 2007).

Conforme apresentado na tabela 1, o estado do Paraná obtém participação crescente da atividade, ao longo do triênio de 2006-2008. Em 2006 existiam 4.097 estabelecimentos, passando em 2008 para 4.567 estabelecimentos contribuindo com $9,11 \%$ na geração de empregos do setor. Ao longo do período, o estado superou produtores respeitáveis do segmento como Rio de Janeiro e Rio Grande do Sul e atualmente se encontra em quarto lugar nacional. À frente do estado paranaense, a partir de dados secundários da RAIS/MTE (2008), encontram-se São Paulo (14.006 estabelecimentos e participação relativa de 27,94\%), Minas Gerais (6.932 estabelecimentos e participação relativa de $13,83 \%$ ) e Santa Catarina (6.576 estabelecimentos e participação relativa de $13,11 \%$ ). Pode-se verificar que a participação relativa do Paraná vem aumentando ao longo desses anos em detrimento da redução relativa, principalmente, dos Estados de Minas Gerais, Goiás e Rio de Janeiro.

Tabela 1- Número de estabelecimentos do setor de Confecção, por unidades da Federação em 2006, 2007 e 2008

\begin{tabular}{lcccccc}
\hline Unidade da Federação & $\mathbf{2 0 0 6}$ & $\mathbf{\%}$ & $\mathbf{2 0 0 7}$ & $\mathbf{\%}$ & $\mathbf{2 0 0 8}$ & $\mathbf{\%}$ \\
\hline São Paulo & 12.838 & 28,08 & 13.272 & 27,93 & 14.006 & 27,94 \\
Minas Gerais & 6.512 & 14,25 & 6.637 & 13,97 & 6.932 & 13,83 \\
Santa Catarina & 5.758 & 12,59 & 6.156 & 12,95 & 6.576 & 13,11 \\
Paraná & $\mathbf{4 . 0 9 7}$ & $\mathbf{8 , 9 6}$ & $\mathbf{4 . 2 8 2}$ & $\mathbf{9 , 0 1}$ & $\mathbf{4 . 5 6 7}$ & $\mathbf{9 , 1 1}$ \\
Rio de Janeiro & 3.108 & 6,79 & 3.191 & 6,72 & 3.419 & 6,82 \\
Goiás & 2.524 & 5,52 & 2.578 & 5,43 & 2.705 & 5,39 \\
Rio Grande do Sul & 2.719 & 5,95 & 2.780 & 5,85 & 2.869 & 5,72 \\
Ceará & 2.223 & 4,86 & 2.434 & 5,12 & 2.670 & 5,33 \\
Demais Unidades & 5.933 & 12,98 & 6.181 & 13,01 & 6.384 & 12,74 \\
\hline BRASIL & $\mathbf{4 5 . 7 1 2}$ & $\mathbf{1 0 0 , 0 0}$ & $\mathbf{4 7 . 5 1 1}$ & $\mathbf{1 0 0 , 0 0}$ & $\mathbf{5 0 . 1 2 8}$ & $\mathbf{1 0 0 , 0 0}$
\end{tabular}

Fonte: Elaboração própria a partir dos dados da RAIS/MTE (2008).

Cabe destacar que o APL de bonés do município de Apucarana é responsável por $86 \%$ da produção nacional de bonés. 


\subsection{Caracterização do APL de Apucarana}

O município de Apucarana foi identificado pelo governo federal como um Arranjo Produtivo Local, tornando-se uma referência nacional na confecção de bonés. Utilizando-se da tipologia proposta por Suzigan et al. (2003), o APL de Apucarana configura-se como um Núcleo de Desenvolvimento Setorial e Regional (NDSR), ou seja, um arranjo produtivo local que se destaca pela importância relativa para a região e pela influência da atividade por ele desenvolvida no Estado. Ainda segundo o autor (2003, p. 11) essa dupla importância dos APLs para uma região e para o setor a que pertencem é que o torna um Núcleo de Desenvolvimento Setorial e Regional.

Ainda com o propósito de caracterizar o objeto de análise busca-se evidenciar elementos tais como: os processos e ações de comercialização; a capacitação gerencial e qualificação da mão-de-obra; a relação com fornecedores; as inovações tecnológicas e as formas de cooperação e fontes de financiamento desenvolvidas pelo APL de boneleiro.

A venda dos produtos da maioria das empresas do arranjo acontece por meio de representantes comerciais (vendedores externos); vendedores próprios das empresas e transações via telemarketing. A falta de uma estrutura de comercialização consistente e dinâmica é que reduz as condições de um desenvolvimento mais autônomo, independente dos agentes externos no APL (Censo Industrial, 2006).

O ramo confeccionista de bonés e artigos correlatos é intensivo em mão-de-obra, absorvendo grande número de trabalhadores, em sua maioria, com baixa qualificação formal. As categorias ocupacionais são do tipo tradicional, como costureiras e bordadeiras, mas algumas exigem certo grau de conhecimento para execução de operações técnicas e de equipamentos mais modernos. As instituições de apoio desenvolvem treinamentos formais por meio da oferta de cursos profissionalizantes, e é por meio do aprender fazendo (learning by doing) que a maioria da mão-de-obra local se qualifica para o APL (IPARDES, Nota Técnica, 2006).

A presença de um grande número de fornecedores de matérias-prima e insumos alojados no município propicia uma maior concentração da cadeia produtiva local, reduzindo os custos e proporcionando um intercâmbio maior entre os elos produtivos. Além desses fatores, confirmam-se a atuação de profissionais de marketing, técnicas de processos, vendas, criação 
Identificação e avaliação das ações institucionais e políticas públicas com foco nas demandas do Arranjo Produtivo Local (APL) de bonés de Apucarana no Estado do Paraná

visual e manutenção, dentre outros. Os empresários do segmento de bonés de Apucarana estão incorporando novas técnicas no processo produtivo e na gestão empresarial.

Em 1997, as empresas iniciaram o processo de cooperação formando a Associação Brasileira dos Fabricantes de Bonés de Qualidade (ABRAFAB'Q), que elaborou e viabilizou um projeto de exportação com o apoio da Agência Brasileira de Promoção de Exportação e Investimentos (APEX), adquirindo certificações ISO 9000 e uma central de compras conjunta (IPARDES, Nota Técnica, 2006, p.09). Outra iniciativa importante foi a constituição da Associação das Indústrias de Bonés e Brindes de Apucarana (ASSIBBRA), composta por dezessete empresas, que objetivam a operacionalização da central de compras, a formação de estoques reguladores e a produção conjunta de insumos para a montagem de bonés.

Mas foi através de iniciativas do SEBRAE junto aos empresários e entidades locais que o conceito de APL foi socializado e disseminado. Outras instituições também desempenham papel fundamental no desenvolvimento do arranjo, como o SENAI, o Centro Moda, o Sindicato da Indústria do Vestuário de Apucarana e Vale do Ivaí (SIVALE), a Prefeitura de Apucarana, a Associação Comercial, Industrial e de Serviços de Apucarana (ACIA) e o Instituto Euvaldo Lodi (IEL).

Essas ações propiciaram às empresas associadas o acesso às matériasprima e a preços mais competitivos, em virtude da compra conjunta. Por meio de negociações, as associações firmaram um acordo com os fabricantes de tecido para o fornecimento da matéria-prima em sistema de comodato, proporcionando às empresas economia de tempo, redução de custos e incremento da eficiência. Com o apoio de instituições de capacitação e tecnologia do município estão realizando iniciativas entre empresas confeccionistas e fornecedores do APL a fim de aprimorar esta relação. A realização do Censo Industrial do arranjo foi considerada pelas lideranças locais uma das ações cooperativas mais significativas para o aglomerado, pois agregou o esforço de várias instituições locais e externas vinculadas nesse importante projeto (IPARDES, Nota Técnica, 2006).

O setor passa por algumas necessidades de fontes de financiamento, visando à aquisição de máquinas e equipamentos. Outro entrave é a melhora na qualificação da mão-de-obra, que na visão dos empresários locais é um fator contribuinte para a ocorrência de um desenvolvimento garantido do setor. 


\subsection{Identificação e avaliação das ações institucionais e de políticas públicas}

No transcorrer desta seção busca-se identificar as principais ações institucionais implementadas nos últimos três anos (2006 a 2008) e avaliar tais ações desenvolvidas pelas instituições de apoio a fim de suprir as demandas identificadas pelos empresários do APL confeccionista de bonés de Apucarana.

Por meio do quadro 3 , evidenciam-se as demandas ${ }^{10}$ identificadas em 2005, e presentes no Projeto de Identificação, Caracterização, Construção de Tipologia e Apoio na Formulação de Políticas para Arranjos Produtivos Locais (APLs), que foi publicado em 2006 e desenvolvido pela Secretaria de Estado do Planejamento e Coordenação Geral (SEPL), pelo Instituto Paranaense de Desenvolvimento Econômico e Social (IPARDES) e pelas Instituições Estaduais de Ensino Superior (IEES).

\begin{tabular}{|c|}
\hline DEMANDAS IDENTIFICADAS \\
\hline $\begin{array}{l}\text { 1. Subsidiar, por intermédio de estudos e ações, o desenvolvimento de estratégias de } \\
\text { expansão do mercado interno e externo. }\end{array}$ \\
\hline $\begin{array}{l}\text { 2. Implementar técnicas modernas, profissionalizantes para o setor de gestão empre- } \\
\text { sarial. }\end{array}$ \\
\hline $\begin{array}{l}\text { 3. Ampliar as vagas nos cursos de qualificação da mão-de-obra local e apoiar a insti- } \\
\text { tuição de outros cursos para suprir as demandas das empresas. }\end{array}$ \\
\hline 4. Criar mecanismos de inserção do APL no mercado externo. \\
\hline $\begin{array}{l}\text { 5. Apoiar a instituição de programa de marketing, visando à divulgação da imagem do } \\
\text { APL no mercado doméstico e no exterior. }\end{array}$ \\
\hline $\begin{array}{l}\text { 6. Viabilizar a participação dos empresários do arranjo em eventos nacionais e inter- } \\
\text { nacionais específicos do ramo. }\end{array}$ \\
\hline $\begin{array}{l}\text { 7. Orientar os empresários sobre mecanismos de financiamento, bem como estimular } \\
\text { a criação de cooperativas de crédito específicas para o setor. }\end{array}$ \\
\hline $\begin{array}{l}\text { 8. Criar programas de capacitação empresarial visando otimizar os níveis de qu } \\
\text { e eficiência produtiva. }\end{array}$ \\
\hline
\end{tabular}

Quadro 3 - Demandas Identificadas para o caso do APL de bonés de Apucarana.

Fonte: Arranjo produtivo local de bonés de Apucarana: nota técnica/ Instituto Paranaense de Desenvolvimento Econômico e Social, Secretaria de Estado do Planejamento e Coordenação Geral. - Curitiba: IPARDES, 2006. p.29.

\footnotetext{
10 Informações extraídas da publicação: Arranjo produtivo local de bonés de Apucarana: nota técnica/ Instituto Paranaense de Desenvolvimento Econômico e Social, Secretaria de Estado do Planejamento e Coordenação Geral. - Curitiba: IPARDES, 2006. p.29.
} 
Identificação e avaliação das ações institucionais e políticas públicas com foco nas demandas do Arranjo Produtivo Local (APL) de bonés de Apucarana no Estado do Paraná

De acordo com o Plano de Desenvolvimento do APL de Boné de Apucarana - Paraná (2005, pág. 31-41) e dos sítios da internet, algumas ações foram previstas e concretizadas, ao longo do período de 2005 a 2008. Por meio destas ações observou-se que a maioria foi executada com o intuito de inserir o APL no mercado externo de forma competitiva e expandir sua comercialização junto ao mercado interno.

Para atender a demanda que considera o desenvolvimento estratégico de expansão direcionado ao mercado interno, por intermédio de estudos e ações, foi realizado pelo Instituto Paranaense de Desenvolvimento Econômico e Social (IPARDES) um levantamento do perfil das empresas do APL de Bonés de Apucarana no período de setembro/2005. E também, publicaram boletins informativos voltados à disseminação de informações sobre o arranjo para todas as empresas e parceiros comerciais. Por meio destas realizações, ocorreu uma ampliação na base de dados secundários relacionados às empresas locais e à atividade produtiva, possibilitando um maior conhecimento do perfil do setor boneleiro local.

A construção e implementação de barracões industriais, com maior área e melhor infraestrutura, permitiu a expansão da capacidade instalada desta estrutura de produção industrial. A importância destas obras, que aconteceram via ações conjuntas da Secretaria de Estado da Indústria, Comércio e Assuntos do MERCOSUL e da Prefeitura de Apucarana, consiste em poder sustentar o crescimento da produção e atender de forma satisfatória toda a demanda existente.

Diante deste contexto, cabe destacar uma das políticas de apoio destinada ao Arranjo Produtivo de bonés de Apucarana que impulsionará o ritmo da produção de bonés local. Foi aprovado o projeto de Lei 2.728/2007, que institui a obrigatoriedade do uso de uniforme estudantil padronizado nas escolas públicas, incluindo o boné, pela Comissão de Educação e Cultura da Câmara dos Deputados. Com isso, o setor boneleiro terá o desafio de confeccionar 100 milhões de bonés para atender os estudantes da $1^{\mathrm{a}}$ a $9^{\mathrm{a}}$ série da Educação Básica da rede pública de ensino. Esta informação foi promulgada pelo presidente da Frente Parlamentar Têxtil, deputado federal, Rodrigo Rocha Loures (PMDB), durante reunião com empresários do setor, em Apucarana. $\mathrm{O}$ kit do uniforme escolar já foi aprovado no próximo orçamento do governo Federal (Portal do Boné, Notícias, 2008).

Por fim, também com o propósito de promoção ao mercado interno, e principalmente evitar externalidades negativas por meio de responsabilidade 
socioambiental, implementou-se um programa para o reaproveitamento econômico dos resíduos industriais e sobras.

O programa de levantamento de resíduos gerados pela cadeia produtiva de bonés foi um grande avanço exercido pelo arranjo em termos de utilidade. Vários cursos foram ministrados para os empresários do setor visando à capacitação das empresas e sua inserção no mercado. Para a manutenção satisfatória deste programa, o segmento recebe contínuo apoio da Universidade Tecnológica Federal do Paraná (UTFPR- Campus Apucarana) e da Prefeitura de Apucarana.

Para divulgar a imagem do arranjo tanto ao mercado doméstico quanto no exterior, executou-se um programa de marketing bem diversificado. Inicialmente, criou-se uma logomarca institucional, desenvolvida em parceria pelo SIVALE, SEBRAE-PR e pelo Centro Tecnológico de Desenvolvimento Profissional Norte do Paraná (Centro Moda). Também institui-se uma nomenclatura exclusiva para as exportações de bonés direcionadas ao MERCOSUL. A nova Nomenclatura Comum do MERCOSUL (NCM) foi publicada pela Câmara de Comércio Exterior (CAMEX) ${ }^{11}$.

A obtenção de um espaço para a promoção de feiras, congressos e eventos relacionados ao produto possibilitou intensificar a identidade territorial. Além de várias ações de marketing que foram articuladas pelo APL, como o Dia do Boné, que é comemorado todo dia 31 de janeiro. A data foi criada há três anos pelo Arranjo Produtivo Bonés de Apucarana, e tem como finalidade divulgar a atividade e valorizar as pessoas que trabalham nesse segmento.

Para diminuir a distância entre os usuários e os últimos lançamentos da cadeia produtiva de bonés, uma ação poderosa do marketing foi a criação do endereço eletrônico "Portal do Boné". O e-commerce, sistema de compra e venda pela internet, será inaugurado futuramente e poderá ser acessado por meio do banner Vitrine do Boné na página do www.portaldobone.com.br. Em poucos anos, o "Portal do Boné" se consolidou como vetor de informações relacionadas a boné tanto para empresários do setor e estudantes que pesquisam sobre o acessório quanto para quem quer comprar o produto em pequena e grande escala. Órgãos de imprensa também têm o "Portal" como fonte de pesquisa e pauta, quando o assunto é boné.

Com a resolução publicada pela Câmara de Comércio Exterior (CAMEX) n 18, de 26/03 /2009, o boné será identificado pelo número 6505.90.I. 
Identificação e avaliação das ações institucionais e políticas públicas com foco nas demandas do Arranjo Produtivo Local (APL) de bonés de Apucarana no Estado do Paraná

Para viabilizar a participação dos empresários locais em eventos nacionais e internacionais específicos do ramo, pode-se mencionar a realização da feira nacional de fornecedores de matérias-primas para indústrias de bonés, brindes e acessórios e a convenção brasileira de fabricantes de bonés, brindes e similares (EXPO BONÉ). Tal evento, que se realiza anualmente, promove $\mathrm{o}(\mathrm{s})$ produto(s) no mercado interno e externo, valoriza a identidade local e apresenta novas tecnologias e inovações direcionadas ao setor.

Nos últimos anos a Feira Nacional do Setor de Bonés, Camisetas, Brindes e Similares (EXPO BONÉ), realizada em Apucarana, têm adquirido grande projeção em contexto estadual e nacional. Com uma infraestrutura composta por vários expositores, máquinas, matérias-primas e acessórios para a indústria, além de produtos finais para magazines e lojas de bonés e camisetas proporcionou ao evento uma ótima alocação física e satisfação total dos organizadores e participantes. O pólo produtivo de bonés de Apucarana ampliou sua participação nesta feira nos últimos anos. O evento é considerado a maior Feira de Brindes, Produtos Promocionais, Presentes Corporativos \& Mídia Extensiva do Brasil (EXPO BRÍNDICE, 2007-2009).

Uma das realizações de maior destaque, direcionada ao mercado externo, foi a participação das "missões" internacionais, comerciais e de promoção do segmento, dado que empreender em novos mercados sempre foi uma das principais metas do Arranjo de Bonés de Apucarana.

O propósito de participar destas "missões" internacionais reside em promover o(s) produto(s) no mercado externo, melhorar a qualidade e apresentação do(s) produto(s), aplicar novas tecnologias tornando-o(s) mais competitivo(s), consolidar novos mercados, agregar valor e internacionalizar as empresas do setor boneleiro. Uma missão empresarial conjunta entre o APL de Apucarana, o Arranjo de Móveis de Arapongas e o SEBRAE-PR levou alguns empresários e representantes de entidades ligadas aos dois setores a 104a "Canton Fair", na China em 2008. Os empresários conheceram a Feira de Cantão, que é considerada um dos maiores eventos da atualidade em tecnologia e inovação. A viagem empresarial à China proporcionou aos empresários da cadeia produtiva de bonés conhecerem melhor a economia chinesa (Portal do Boné, Notícias, 2008).

Com vistas a ampliar as vagas nos cursos de qualificação da mão-deobra local e apoiar as instituições de outros cursos para suprir as demandas identificadas foi realizada uma parceria entre as instituições locais e os go- 
vernos Federal, Estadual e Municipal. Por meio desta ação conjunta pode-se obter durante o ano de 2008, a abertura do Curso Superior de Tecnologia em Processos Químicos da UTFPR, que será ministrado na unidade de Apucarana. Outra realização que beneficiou o arranjo com profissionais cada vez mais capacitados foi o desenvolvimento de programas educacionais para alavancar o nível da escolaridade da mão-de-obra local e aumentar a capacitação destes profissionais.

Com a aspiração de aperfeiçoar a qualidade e eficiência produtiva, por meio de programas de capacitação empresarial, algumas instituições de apoio, juntamente com a forte cooperação entre os agentes locais desenvolveram programas tecnológicos industriais. Tais programas tem como propósito aumentar a vantagem competitiva e incorporar conceitos de design aos produtos do APL boneleiro para atender à demanda internacional.

A implementação de um núcleo de inteligência ao arranjo, com novos laboratórios foi concretizada pela Secretaria de Estado de Ciência, Tecnologia e Ensino Superior (SETI), o Instituto de Tecnologia do Paraná (TECPAR), SIVALE, ACIA, SEBRAE-PR e o Centro Moda. Esse núcleo é responsável por monitorar o mercado, as inovações tecnológicas, bench star e bench marketing e conscientizar sobre a importância da formalização das micro e pequenas empresas (Censo Industrial do APL de Confecção de bonés de Apucarana, 2006).

Além disso, o SIVALE, Centro Moda, SEBRAE-PR, UEL, Ministério do Desenvolvimento da Indústria e Comércio Exterior (MDIC) e Agência Brasileira de Promoção de Exportação e Investimentos (APEX) instalaram laboratórios para atender as exigências da demanda do APL boneleiro. Os recursos utilizados por estes laboratórios incluem a inovação e a aplicação de novas tecnologias, com o propósito de qualificar os profissionais locais, agregar valor ao produto, incrementar a competitividade e promover a cultura exportadora empresarial no APL.

Para melhorar a eficiência da produção com maior qualificação dos fornecedores a partir de novas tecnologias e inovações (incluindo design), os empresários locais programaram treinamentos de telemarketing, gestão financeira e de recursos humanos e gestão para os fornecedores de matérias-primas e acessórios do APL. Adicionalmente, com a ajuda do SEBRAE-PR e do Centro Moda foram realizadas consultorias especializadas em modernas técnicas em processos de gestão de qualidade e planejamento e estratégia de produção. 
Identificação e avaliação das ações institucionais e políticas públicas com foco nas demandas do Arranjo Produtivo Local (APL) de bonés de Apucarana no Estado do Paraná

De modo geral, para que o setor de gestão empresarial pudesse implementar técnicas modernas e profissionalizantes, foi colocado em prática o Plano de Ações do APL. Este Plano incluiu a realização de pesquisas, com o propósito de aumentar o conjunto de informações e possibilitar uma avaliação mais qualificada dos resultados obtidos (Plano de Desenvolvimento do APL de Boné de Apucarana, 2006).

Como abordado detalhadamente ao longo desta seção, foram apresentado as várias ações desenvolvidas pelas instituições de apoio que tem como finalidade aumentar os níveis de competitividade do arranjo ${ }^{12}$. Com o apoio das instituições, empresariado local e de políticas públicas em níveis Federal, Estadual e Municipal as ações descritas anteriormente possibilitaram que as demandas identificadas fossem parcialmente supridas. Porém, não foi encontrada nenhuma realização que atendesse especificamente a necessidade de orientação aos empresários sobre mecanismos de financiamento, bem como a criação de cooperativas de crédito específicas para o setor. Portanto, manifesta-se uma expectativa para que futuramente novas ações sejam desenvolvidas neste sentido.

\subsection{Evolução do APL de bonés de Apucarana no contexto das trans- formações dos anos recentes}

Esta seção procura contextualizar e caracterizar a atividade de confecção de bonés de Apucarana por meio da análise de duas variáveis consideradas importantes, número de estabelecimentos e de empregos formais ${ }^{13}$. Também, estende-se a análise para uma averiguação evolutiva do nível de especialização do APL, utilizando-se da metodologia do cálculo do Quociente Locacional (QL) para o período de 2000 a 2008. E por fim, avaliam-se os impactos das políticas públicas e das ações institucionais descritas na seção anterior como incentivo ao arranjo.

No município de Apucarana encontram-se duas grandes empresas atuantes nas áreas de fiação, tecelagem e acabamento de tecidos. Essas empresas são fornecedoras de matérias-primas que abastecem indústrias regionais e também para todo o Brasil.

\footnotetext{
${ }_{12}$ Dentre as ações destacam-se: a promoção do(s) produto(s) no mercado interno e externo, a valorização da identidade local, a melhorar da capacitação e formação profissional, a inserção de novas tecnologias e inovações e o suporte direcionado à expansão do nível de capacidade instalada no APL.

13 Neste caso, o período compreende o triênio de 2006-2008.
} 
Relacionados ao ramo do vestuário, tem-se dois segmentos: o de confecção de bonés e o de confecção de uniformes e vestuário de segurança, sendo que a maior empresa nacional que atende o mercado de calçados de segurança está instalada em Apucarana. O segmento de bonés concentra um número significativo de estabelecimentos no município de Apucarana, e evidencia-se nacionalmente como o maior pólo de confecções de bonés do país (IPARDES, Nota Técnica, 2006).

Pode-se observar por meio da tabela 2 e de forma desagregada, ou seja, por Classe da CNAE 2.0, que a Classe 1.414-2: "Fabricação de acessórios do vestuário, exceto para segurança e proteção, composta pela fabricação de gravatas, lenços, cintos, suspensórios, luvas (inclusive de couro), leques, xales, echarpes, chapéus, boinas, bonés, gorros e outros" é a de maior destaque. Em 2006 a participação relativa do segmento foi de 49,31\%, com 215 estabelecimentos. No ano seguinte aumentou o número de estabelecimentos para 225 , porém a participação relativa decresceu para 48,7\%. No ano de 2008, Apucarana possuía 220 estabelecimentos, queda de 5 estabelecimentos em relação a 2007, e declínio na participação relativa de 3,06\%, ficando com 45,64\% (RAIS/MTE 2008).

Tabela 2 - Número de estabelecimentos no Setor de Confecção do APL de Apucarana no Estado do Paraná nos anos de 2006, 2007 e 2008

\begin{tabular}{|c|c|c|c|c|c|c|}
\hline $\begin{array}{c}\text { Estabelecimentos } \\
\text { Classe de Atividade Econômica } \\
\text { (CNAE 2.0) }\end{array}$ & 2006 & $\%$ & 2007 & $\%$ & 2008 & $\%$ \\
\hline $\begin{array}{l}\text { CLASSE 1.411-8 Confecção de roupas } \\
\text { íntimas }\end{array}$ & 16 & 3,67 & 18 & 3,9 & 16 & 3,32 \\
\hline $\begin{array}{l}\text { CLASSE 1.412-6 Confecção de peças } \\
\text { do vestuário, exceto roupas íntimas }\end{array}$ & 186 & 42,6 & 201 & 43,51 & 227 & 47,1 \\
\hline $\begin{array}{l}\text { CLASSE 1.413-4 Confecção de roupas } \\
\text { profissionais }\end{array}$ & 12 & 2,75 & 12 & 2,6 & 13 & 2,7 \\
\hline $\begin{array}{l}\text { CLASSE 1.414-2 Fabricação de } \\
\text { acessórios do vestuário, exceto para } \\
\text { segurança e proteção }\end{array}$ & 215 & 49,3 & 225 & 48,7 & 220 & 45,6 \\
\hline CLASSE 1.421-5 Fabricação de meias & 0 & 0 & 0 & 0 & 0 & 0 \\
\hline $\begin{array}{l}\text { CLASSE 1.422-3 Fabricação de artigos } \\
\text { do vestuário, produzidos em malharias e } \\
\text { tricotagens, exceto meias }\end{array}$ & 7 & 1,61 & 6 & 1,3 & 6 & 1,24 \\
\hline Total & 436 & 100 & 462 & 100 & 482 & 100 \\
\hline
\end{tabular}


Identificação e avaliação das ações institucionais e políticas públicas com foco nas demandas do Arranjo Produtivo Local (APL) de bonés de Apucarana no Estado do Paraná

Verificou-se por meio da tabela 3 uma importante participação relativa no número de empregos formais no município de Apucarana. Existiam em 2006, 3.508 empregados com participação relativa de 56,04\% passando, em 2007 para 3.801 com participação relativa de 56,11\%. Ocorreu, portanto a inserção de 293 novos empregos que representaram 0,07\% de aumento na participação relativa. No ano de 2008, o número de empregos formais reduziu-se para 3.444, corte de 357 empregos e participação relativa de 49,65\% (RAIS/MTE 2008).

Tabela 3 - Número de empregados no Setor de Confecção do APL de Apucarana no Estado do Paraná nos anos de 2006, 2007 e 2008

\begin{tabular}{|c|c|c|c|c|c|c|}
\hline $\begin{array}{c}\text { Empregos } \\
\text { Classe de Atividade Econômica } \\
\text { (CNAE 2.0) }\end{array}$ & 2006 & $\%$ & 2007 & $\%$ & 2008 & $\%$ \\
\hline $\begin{array}{l}\text { CLASSE 1.411-8 Confecção de } \\
\text { roupas íntimas }\end{array}$ & 99 & 1,58 & 135 & 1,99 & 106 & 1,53 \\
\hline $\begin{array}{l}\text { CLASSE 1.412-6 Confecção de peças } \\
\text { do vestuário, exceto roupas íntimas }\end{array}$ & 2.337 & 37,33 & 2.679 & 39,55 & 3.134 & 45,18 \\
\hline $\begin{array}{l}\text { CLASSE 1.413-4 Confecção de } \\
\text { roupas profissionais }\end{array}$ & 295 & 4,71 & 125 & 1,85 & 199 & 2,87 \\
\hline $\begin{array}{l}\text { CLASSE 1.414-2 Fabricação de } \\
\text { acessórios do vestuário, exceto } \\
\text { para segurança e proteção }\end{array}$ & 3.508 & 56,04 & 3.801 & 56,11 & 3.444 & 49,65 \\
\hline $\begin{array}{l}\text { CLASSE 1.421-5 Fabricação de } \\
\text { meias }\end{array}$ & 0 & 0 & 0 & 0 & 0 & 0 \\
\hline $\begin{array}{l}\text { CLASSE 1.422-3 Fabricação de arti- } \\
\text { gos do vestuário, produzidos em ma- } \\
\text { Iharias e tricotagens, exceto meias }\end{array}$ & 21 & 0,34 & 34 & 0,5 & 54 & 0,78 \\
\hline Total & 6.260 & 100 & 6.774 & 100 & 6.937 & 100 \\
\hline
\end{tabular}

Fonte: Elaboração própria a partir dos dados da RAIS/MTE (2008).

Segundo os dados secundários da RAIS/MTE 2008, no período de 2006 a 2008, houve uma redução de 3,67\% no número de estabelecimentos no APL boneleiro de Apucarana e de 6,39\% nos empregos formais do segmento. Essas quedas podem ser explicadas em grande parte pela desaceleração do nível da atividade econômica nacional frente à crise financeira mundial.

As empresas menores encontram mais dificuldade para recuperar-se porque são mais dependentes de recursos de terceiros, que ainda não se nor- 
malizaram após a crise. Com o crescimento econômico do país, acredita-se em uma redução dos registros de falências e recuperações judiciais, apesar dos problemas que ainda serão enfrentados pelos exportadores com o câmbio e a demanda dos países compradores (Agência Estadual de Notícias, 2009).

Em seguida, analisa-se a trajetória dos índices de especialização $(\mathrm{QL})^{14}$ ao longo dos anos de 2000 a 2008 da atividade confeccionista de bonés de Apucarana e do Estado paranaense, apresentada por meio do gráfico 1.

Os Quocientes Locacionais calculados ao longo do período pesquisado, 2000 a 2008, apresentaram-se maiores que um (QL > 1), ou seja, a especialização do município de Apucarana na atividade industrial de bonés é superior à especialização do Estado do Paraná nessa atividade $\left(\mathrm{QL}_{\text {Apucarana }}\right)$ e a especialização do Estado do Paraná na confecção de bonés é superior à especialização nacional nesta mesma atividade $\left(\mathrm{QL}_{\text {Paraná }}\right)$.

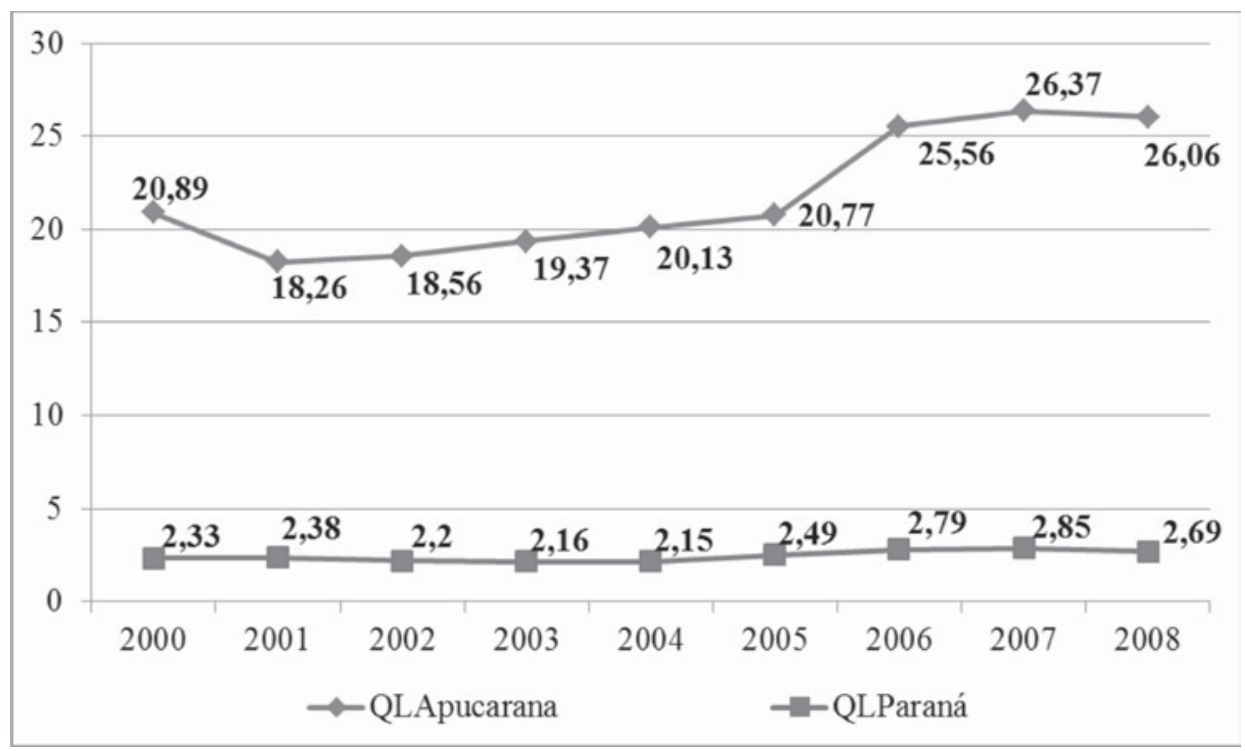

Gráfico 1 - Índice de Especialização (QL) do APL de bonés de Apucarana e do Estado do Paraná no período de 2000 a 2008

Fonte: Elaboração própria a partir dos dados da RAIS/MTE (2008).

${ }^{14}$ O Coeficiente Locacional corresponde à razão entre a participação do arranjo de confecção de bonés (Classe I.4 I 4 2) na indústria de transformação de Apucarana e a participação desse mesmo setor na indústria de transformação do Estado do Paraná ( $\left.\mathrm{QL}_{\text {Apucarana }}\right)$; e a razão entre a participação da atividade de confecção de bonés na indústria de transformação do Paraná e a participação da mesma na indústria de transformação do Brasil ( $\left(\mathrm{L}_{\text {Paranâ }}\right)$. 
Identificação e avaliação das ações institucionais e políticas públicas com foco nas demandas do Arranjo Produtivo Local (APL) de bonés de Apucarana no Estado do Paraná

Os $\mathrm{QL}_{\text {Apucarana }}$ e $\mathrm{QL}_{\text {Paraná }}$ apresentaram uma trajetória de queda até atingirem um ponto de mínino em 2001 (ponto de inflexão: 18,26), ocorrendo após uma inversão na trajetória e esses passaram a crescer, atingindo em 2007 os pontos máximos da série com 26,37 ( $\left.\mathrm{QL}_{\text {Apucarana }}\right)$ e 2,85 $\left(\mathrm{QL}_{\text {Paraná }}\right)$, como apresentado por meio do gráfico 1. Já no ano de 2008 ocorreu uma leve queda na trajetória de especialização do APL confeccionista boneleiro de Apucarana e também do Estado paranaense. (RAIS/MTE 2008).

Diante das constatações obtidas por meio das análises desta seção, o Arranjo Produtivo Local de bonés de Apucarana mostrou-se muito eficiente na geração de emprego e renda local. Os números de estabelecimentos e empregos formais entre 2006 a 2008 foram bem significativos, evidenciando a importância do arranjo para o município e região. Somente no ano de 2008, devido à crise financeira internacional, que a expansão do segmento ficou comprometida e os números sofreram leve queda.

Por meio da análise da trajetória do Quociente Locacional (QL), verificou-se que o APL manteve uma elevada especialização ao longo dos anos de 2000 a 2008. E também, uma posição bem superior da especialização local quando comparada com a especialização do Estado do Paraná em tal atividade produtiva. As políticas públicas e as ações institucionais articuladas durante o período estudado foram muito importantes para intensificar a dinâmica desta estrutura produtiva, proporcionando efeitos positivos em torno do Arranjo Produtivo Local.

\section{CONSIDERAÇÕES FINAIS}

O objetivo central deste trabalho foi evidenciar as demandas apresentadas pelos empresários do setor de confecção de bonés de Apucarana, bem como identificar e avaliar as ações institucionais e as políticas públicas, com foco nas necessidades apontadas nos relatórios desenvolvidos pelo IPARDES (Instituto Paranaense de Desenvolvimento Econômico e Social), órgão vinculado à SEPL.

Especificamente para o caso do Arranjo Produtivo Local de bonés de Apucarana, foram identificadas algumas demandas, tais como: subsidiar, por intermédio de estudos e ações, o desenvolvimento de estratégias de expansão do mercado interno e externo e criar mecanismos de inserção 
do APL no mercado externo; apoiar a instituição de programa de marketing, visando à divulgação da imagem do APL no mercado doméstico e no exterior e viabilizar a participação dos empresários do arranjo em eventos nacionais e internacionais específicos do ramo; programar técnicas modernas, profissionalizantes para o setor de gestão empresarial e ampliar as vagas nos cursos de qualificação da mão-de-obra local e apoiar a instituição de outros cursos para suprir as demandas das empresas; e orientar os empresários sobre mecanismos de financiamento, bem como estimular a criação de cooperativas de crédito específicas para o setor e criar programas de capacitação empresarial visando otimizar os níveis de qualidade e eficiência produtiva.

Algumas ações institucionais e de políticas públicas foram executadas em benefício do APL de bonés de Apucarana. Averiguou-se que a maior parte das ações foi concretizada visando inserir o APL no mercado externo de forma competitiva e expandir sua comercialização junto ao mercado interno.

Os impactos das políticas públicas e das ações que incentivaram o APL foram avaliados, a partir do desempenho de alguns indicadores considerados importantes. Os resultados obtidos em relação à evolução no número de estabelecimentos e empregos formais entre 2006 a 2008 evidenciaram a importância do APL para o município e região, apresentando números muito expressivos. Mesmo assim, o segmento sentiu os impactos causados pela crise financeira internacional em 2008. Por meio do cálculo do Quociente Locacional (QL), verificou-se que o APL de Apucarana mantém-se com uma sólida especialização produtiva. Neste sentido, verificou-se que as políticas públicas e as ações institucionais executadas durante o período estudado serviram para intensificar a dinâmica desta estrutura produtiva, proporcionando efeitos positivos em torno do arranjo.

De modo geral, concluiu-se que o apoio das instituições locais e de políticas públicas em níveis Federal, Estadual e Municipal possibilitou a realização de ações em favor do APL, com um grau de interação bastante elevado. A execução dessas ações favoreceu para que as demandas fossem parcialmente supridas, proporcionando uma evolução da dinâmica produtiva do Arranjo Produtivo Local (APL) de bonés do município de Apucarana. 
Identificação e avaliação das ações institucionais e políticas públicas com foco nas demandas do Arranjo

Produtivo Local (APL) de bonés de Apucarana no Estado do Paraná

\title{
IDENTIFICATION AND EVALUTION OF THE INSTITUTIONAL ACTIONS AND PUBLIC POLICIES WITH FOCUS IN LOCAL PRODUCTIVE ARRANGEMENT OF HATS AND CAPS OF APU- CARANA (PARANÁ)
}

\begin{abstract}
The objective is to highlight the demands presented by business sector of caps, in Apucarana as well as identify and avaliate institutional actions and public policies, focusing on the needs identified in the report of IPARDES in 2006. The data used are from RAIS / MTE and the State Department of Finance. The method applied was to the calculation of Locational Quotient. The results showed a satisfactory evolution of identified demand with a high degree of interaction between Governments, institutions and support local businesses, allowing the demands were partially met. The number of establishments and formal employment, there was an increase in the first period analyzed, but later the APL felt the effects of international financial crisis. By calculating the Locational Quotient was revealed that the arrangement remains at a high level of expertise, highlighting the positive effects of the regional development.

Keywords: Local Productive Arrangements, Manufacture of caps, Apucarana.
\end{abstract}

\section{REFERÊNCIAS}

ABIT. Associação Brasileira da Indústria Têxtil e de Confecção. Relatório Setorial da Indústria Têxtil Brasileira 2008. Disponível em: $<$ http://www. abit.org.br/> Acesso em: dez. 2009.

ALBAGLI, S.; MACIEL, M. L. Capital social e empreendedorismo local. In: LASTRES, H. M. M.; CASSIOLATO, J. E.; MACIEL, M. L (Org.). Pequena Empresa: cooperação e desenvolvimento local. Rio de Janeiro: Relume Dumará, 2003. 
ARRANJO PRODUTIVO LOCAL de bonés de Apucarana: nota técnica. Instituto Paranaense de Desenvolvimento Econômico e Social, Secretaria de Estado do Planejamento e Coordenação Geral. Curitiba: IPARDES, 2006.

CASSIOLATO, J. E. Principais características a investigar em uma pesquisa de inovação. Estudio Metodológico. La Encuesta de Innovación Tecnológica en las Empresas - $1^{\text {a }}$ Reunião. Rio de Janeiro, p. 25-26, Março, 2002.

EDQUIST, C.; JOHNSON B. Institutions and organizations in systems of innovation. In: EDQUIST, C. (Org.). Systems of innovation technologies, institutions and organizations. New York, Pinter, p.40-63, 1997.

FREEMAN C. The economics of technical change: critical survey. Cambridge Journal of Economics, Cambridge, v. 18, p. 463-514, 1994.

GAROFOLI, G.(2002), Local development in Europe - theoretical models and international comparisons. Disponível em: $<\mathrm{http}: / /$ eur.sagepub. com/cgi/content/abstract/9/3/225> Acesso em jan. 2010.

GORINI, A. P. F. Panorama do setor têxtil no Brasil e no mundo: reestruturação e perspectivas. BNDES Setorial, n. 12, 17-50, 2000.

HIRSCHMAN, A. O. Estratégia de Desenvolvimento Econômico. Editora Fundo de Cultura. Rio de Janeiro, 1960.

IBGE. Instituto Brasileiro de Geografia e Estatística. Cidades@. Disponível em: < http://www.ibge.gov.br/cidadesat> Acesso em: set. 2009.

IPARDES. Instituto Paranaense de Desenvolvimento Econômico e Social. Valor Adicionado Fiscal da Indústria de Transformação. Curitiba, 2008. Microsoft Office Excel (xls).

JOHNSON, R.A.; WICHERN, D.W. Applied Multivariate Statistical Analysis. Prentice- Hall International: New Jersey. 1992. 642 p.

KUPFER, D. Trajetórias de reestruturação da indústria brasileira após a abertura e a estabilização. (Tese de doutorado), Rio de Janeiro, UFRJ, 1998. 
Identificação e avaliação das ações institucionais e políticas públicas com foco nas demandas do Arranjo Produtivo Local (APL) de bonés de Apucarana no Estado do Paraná

LANGLOIS, R., ROBERTSON, P.(1994), Innovation, networks and vertical integration. Disponível em: $<$ http://www.elsevier.com/locate/ econbase> Acesso em: dez. 2009.

LASTRES, H. M. M; CASSIOLATO, J. E. Glossário de Arranjos e Sistemas Produtivos e Inovativos Locais. Rio de Janeiro: Rede de pesquisa em sistemas produtivos e inovativos locais. Novembro de 2003. Disponível em: <http://www.ie.ufrj.br/redesist> Acesso em: 27 mar. 2008.

LEMOS, C. Inovação para Arranjos Produtivos de MPMEs. In: LASTRES, H. M. M. et al. (Coords.) Interagir para competir: promoção de arranjos produtivos e inovativos no Brasil. Brasília: Sebrae, 2002.

LUNDVALL, B. A. National systems of innovation: Towards a theory of innovation and interactive learning. London: Pinter Publishers, p. 1-19, 1992.

MARKUSEN, A., Áreas de atração de investimentos em um espaço econômico cambiante: uma tipologia de distritos industriais. Nova Economia, Belo Horizonte, v.5, nº 2, p. 9 - 44, dez. 1995.

MARSHALL, A. Princípios de Economia: tratado introdutório. São Paulo: Abril Cultural, vol. I, p. 231-238, 1982.

MONTEIRO FILHA, D. C.; SANTOS, A. M. M. Cadeia têxtil: estruturas e estratégias no comércio exterior. BNDES Setorial, Rio de Janeiro, n. 15, 113-136, 2002.

NAPOLEONI, C. O pensamento econômico do século XX. São Paulo: Círculo do Livro, sd. Cap. III. Schumpeter e a teoria do desenvolvimento econômico, 1990.

OLIVEIRA, M. A.; CÂMARA, M. R. G.; BAPTISTA, J. R. V. O setor têxtil-confecções do Paraná e seus segmentos regionais especializados: 2000-2004. Revista de Economia, Curitiba, v. 33, n. 1, p. 83-115, 2007.

PADIS, P. C. Formação de uma economia periférica: o caso paranaense. Curitiba: IPARDES, 2. ed., 2006. 
PERROUX, François. O conceito de pólo de crescimento. In: FAISSOL, Speridião (Org.). Urbanização e regionalização, relações com o desenvolvimento econômico. Rio de Janeiro: IBGE, 1978. p. 97-110.

PORTAL DO BONÉ. Disponível em: < http://www.portaldobone.com.br>. Acesso em: jan. 2010.

PLANO DE DESENVOLVIMENTO DO APL DE BONÉS DE APUCARANA. Disponível em: <http://www.desenvolvimento.gov.br/arquivos/ dwnl_1248271170.pdf $>$. Acesso em: jan. 2010.

RAIS/MTE - Relação Anual de Informações Sociais. Ministério do Trabalho e Emprego (MTE). Disponível em: <http://www.mte.gov.br/pdet/ Acesso/RaisOnLine.asp>. Acesso em: abril 2009.

REDE APL PARANÁ. Disponível em: <http://www.redeapl.pr.gov.br> Acesso em: jun. 2009.

REDESIST. Rede de pesquisa em sistemas produtivos e inovativos locais. Disponível em: <http://www.redesist.ie.ufrj.br> Acesso em: mai. 2007.

SCHMITZ, H. Eficiência coletiva: caminho de crescimento para a indústria de pequeno porte. Ensaios FEE, Porto Alegre, v. 18, n.2, p. 164-200, 1997.

SCHMITZ H.; NADVI, K. Clustering and industrialization: introduction. World Development, United Kingdom, v. 27, n. 9, p. 1503-1514, 1999.

SUZIGAN, W.; GARCIA, R.; FURTADO, J.; SAMPAIO S. Sistemas Locais de Produção: Mapeamento, Tipologia e Sugestões de Políticas. Apresentação na ANPEC - Associação Nacional dos Centros de Pós-graduação em Economia, 2003. 